\title{
Synthesis and Characterization of novel Thiophene and Carbazole-based Polymers - Optical and Electrochemical Characterization
}

\author{
Abdulaziz Ali B. Alghamdi, ${ }^{1, *}$, Abdelqader Imragaa ${ }^{2}$, Essam S. Abdel-Halim ${ }^{1,3}$ and Ahmed Iraqi ${ }^{4}$ \\ ${ }^{1}$ Department of Chemistry, King Saud University, PO Box 2455, Riyadh 11451, Saudi Arabia. \\ ${ }^{2}$ Department of Chemistry, University of Benghazi, Benghazi, Libya. \\ ${ }^{3}$ Textile Research Division, National Research Center, Dokki, Cairo, Egypt. \\ ${ }^{4}$ Department of Chemistry, University of Sheffield, Sheffield S3 7HF, UK. \\ *E-mail: aalghamdia@KSU.EDU.SA
}

doi: $10.20964 / 2016.06 .57$

Received: 25 January 2016 / Accepted: 23 March 2016 / Published: 4 May 2016

A donor/acceptor series of carbazole copolymers, composed of alternating 2,7-linked 3,6-difluoro-9(1-octyl-nonyl)-carbazole units and bithiophene repeated units [P1], 5,7-bis(5-bromothiophen-2-yl)2,3-bis(4-(2-ethylhexyloxy) phenyl) thieno[3,4-b]pyrazine repeated units [P2] and bithiophene mixed with 5,7-bis(5-bromothiophen-2-yl)-2,3-bis(4-(2-ethylhexyloxy) phenyl) thieno[3,4-b]pyrazine repeated units [P3] have been prepared following Suzuki polymerisation procedures. The route of synthesis and characterisation techniques of this novel class of materials, together with their photophysical and electrochemical properties are presented in this study. The polymers were characterised by ${ }^{1} \mathrm{H}$ NMR, ${ }^{13} \mathrm{C}$ NMR and Elemental Analysis. Molecular weights were estimated using gel permeation chromatography (GPC). The thermal stability behaviour for polymers was investigated using thermogravimetric analysis (TGA) and differential scanning calorimetry (DSC). The electronic and photo-physical properties were investigated by use of cyclic voltammetry (CV) and UV-Vis spectroscopy, respectively.

Keywords: Organic solar cell, Conjugated polymer, Band gap

\section{FULL TEXT}

(C) 2016 The Authors. Published by ESG (www.electrochemsci.org). This article is an open access article distributed under the terms and conditions of the Creative Commons Attribution license (http://creativecommons.org/licenses/by/4.0/). 